\title{
Enhanced Light Intensity Increases Flavonol and Anthocyanin Concentrations but Reduces Flavone Levels in the Cotyledons of Common Buckwheat Seedlings
}

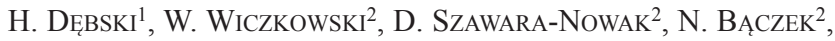 \\ M. SzWED ${ }^{1}$ and M. HorbOWICZ ${ }^{1 *}$ \\ ${ }^{1}$ Department of Plant Physiology and Genetics, Faculty of Natural Sciences, \\ Siedlce University of Natural Sciences and Humanities, 08-110 Siedlce, Prusa 12, Poland \\ ${ }^{2}$ Department of Chemistry and Biodynamics of Food, \\ Institute of Animal Reproduction and Food Research of Polish Academy of Sciences, \\ Tuwima 10, 10-748 Olsztyn, Poland \\ (Received 30 July 2016; Accepted 27 October 2016; \\ Communicated by H. Grausgruber)
}

\begin{abstract}
The effects of two light intensities on the concentration of several flavonoids were investigated in the cotyledons of common buckwheat seedlings. The study was performed on four days old seedlings of cvs. Hruszowska, Panda, Kora and Red Corolla. One group of seedlings was grown under exposure to $180 \pm 20 \mu \mathrm{mol} \cdot \mathrm{m}^{-2} \cdot \mathrm{s}^{-1}$ photosynthetically active radiation, whereas the other group was exposed to $360 \pm 20 \mu \mathrm{mol} \cdot \mathrm{m}^{-2} \cdot \mathrm{s}^{-1}$. The experiment lasted 5 days. The results revealed that light intensity induces changes in the levels of flavonols and flavones. Increased light intensity contributed to a decrease in the concentrations of all flavone $C$-glucosides: orientin (luteolin- 8 - $C$-glucoside) and iso-orientin (luteolin-6- $C$-glucoside), and apigenin: vitexin (apigenin-8- $C$-glucoside) and iso-vitexin (apigenin-6- $C$-glucoside). Simultaneously, a substantial increase in the content of flavonols, i.e. quercetin $O$-glycosides, was found. To the best of our knowledge, this is the first evidence to demonstrate the contrary responses of plant flavonols and flavones to light intensity. The content of anthocyanin also increased under exposure to higher light intensity. Our results indicate that quercetin $O$-glycosides can play a similar role to anthocyanins in the cotyledons of common buckwheat seedlings. Results of correlation analysis indicate that the increase in flavonol and anthocyanin concentrations in response to higher light intensity is maintained through reduced accumulation of flavones and proanthocyanidins.
\end{abstract}

Keywords: common buckwheat, seedling, light intensity, flavonoids

\section{Introduction}

Light is known to regulate plant growth and the biosynthesis of primary and secondary metabolites (Liu et al. 2002; Hemm et al. 2004; Jaakola and Hohtola 2010). The rapid induction of flavonoid biosynthesis under exposure to high-intensity light testifies to the important role played by flavonoids in photoprotection (Gould 2004; Zoratti et al. 2014). Research has demonstrated that the biosynthesis of flavonoids is light dependent, but the *Corresponding author; E-mail: mhorbowicz@uph.edu.pl 
mechanisms involved in this process have not been fully elucidated. In fruit, greater exposure to sunlight increases flavonoid content and, consequently, influences the color and nutritional quality of fruit (Zoratti et al. 2014).

Flavonoids are polyphenolic compounds having the general structure of a 15-carbon skeleton, which consists of two phenyl rings connected by a 3-carbon bridge. Flavonoid biosynthesis takes place through the phenylpropanoid pathway, leading to the formation of their main classes: flavonols, flavones and anthocyanins (Winkel-Shirley 2001). The flavonols are the most widespread of the flavonoids in plant tissues. They include quercetin, kaempferol, and myricetin, but the quercetin is the most ubiquitous. Flavonols in plant tissues are mostly in the form of $O$-glycosides. Flavones are not widely distributed, and are mainly represented in the plants by $C$-glucosides of apigenin and luteolin (Del Rio et al. 2013). Anthocyanins are plant pigments which are responsible for diverse colors of flowers and fruits. In nature, they occur primarily as glycosides of their respective aglycone anthocyanidin. Among anthocyanidins, cyanidin is the most ubiquitous in plants (Gould 2004).

All main classes of flavonoids are present in buckwheat seedling: flavonols, flavones and anthocyanins (Gupta et al. 2011; Horbowicz et al. 2011; Suzuki et al. 2015). Rutin (quercetin-3-rutinoside, or quercetin-3-O-glucosyl-rhamnoside), the major flavonol, occurs in the leaves, stems, flowers and fruit of buckwheat. Apart from the rutin in the seedling of buckwheat occurs quercetin-3-O-galactosyl-rhamnoside. The flavones present in buckwheat seedlings are vitexin (apigenin-8- $C$-glucoside), iso-vitexin (apigenin6- $C$-glucoside), orientin (luteolin-8- $C$-glucoside) and iso-orientin (luteolin-6- $C$-glucoside) (Wiczkowski et al. 2014). The high level of flavonols and flavones in buckwheat leaves is accompanied by anthocyanins. They are accumulated mainly in buckwheat stem, but occur also in leaves where they are masked by chlorophylls. In buckwheat tissues mainly $O$-glycosides of cyanidin are present (Wiczkowski et al. 2014).

Due to their abundance in various classes of flavonoids, buckwheat plants are often used in research to investigate the influence of numerous factors on these compounds (Kalinová and Dadáková 2006, 2012; Kim et al. 2006; Horbowicz et al. 2011, 2015). The green sprouts of common buckwheat are popular in Asian cuisine. Buckwheat sprouts are germinated in darkness for several days, after which they are transferred to light conditions and are harvested when they turn green (Kim et al. 2006).

The aim of this study was to examine the effect of light intensity on the content of particular flavonoids in the cotyledons of common buckwheat seedlings. The observed changes in flavonoid concentrations were compared between the evaluated buckwheat cultivars.

\section{Materials and Methods}

\section{Plant material and treatments}

The study was performed on seedlings of common buckwheat (Fagopyrum esculentum Moench) cvs. Hruszowska, Panda, Kora and Red Corolla. Red Corolla is a cross between $\mathrm{cv}$. Hruszowska and the Buryatskaya population grown in the steppe region of the former 
USSR. Hruszowska has been widely cultivated in Poland since the 1950s. Panda and Kora are genetically close to Hruszowska because they were bred from this cultivar and introduced for commercial use in the 1990s. Seeds of all cultivars have been obtained from Plant Breeding Station, Palikije, Lublin province, Poland.

Four-day-old buckwheat seedlings were grown as described by Horbowicz et al. (2011). The seedlings were transferred to controlled conditions with a 16/8 h light/dark photoperiod and day/night temperature of $24 / 18^{\circ} \mathrm{C}$. They were exposed to photosynthetically active radiation (PAR) with the intensity of $180 \pm 20 \mu \mathrm{mol} \cdot \mathrm{m}^{-2} \cdot \mathrm{s}^{-1}$, which was provided by $400 \mathrm{~W}$ high-pressure sodium lamps (Plantastar 400W E40, Osram, Germany). The seedlings were grown in one-fifth Hoagland solution (Horbowicz et al. 2011). After two days of incubation, buckwheat seedlings were divided into two batches. One batch was exposed to $180 \pm 20 \mu \mathrm{mol} \cdot \mathrm{m}^{-2} \cdot \mathrm{s}^{-1}$ PAR and the other batch to $360 \pm 20$ $\mu \mathrm{mol} \cdot \mathrm{m}^{-2} \cdot \mathrm{s}^{-1} \mathrm{PAR}$. The experiment lasted 5 days. Light intensity was controlled by positioning lamps at an appropriate height, and it was measured with the HD2102.1 portable Photo-Radiometer equipped with the LP 471 PAR probe (Delta OHM, Italy). At the end of the experiment, cotyledons were sampled from 20-25 seedlings per replicate and analyzed to determine the concentrations of flavones, flavonols, anthocyanins and proanthocyanidins. Before analyses, the samples were freeze-dried in a laboratory freeze dryer (Alpha 1-2 LD plus; Christ, Germany) and ground in a Tube Mill (IKA, Germany). The content of flavonoids and total phenolics was expressed on a dry weight basis obtained by freeze-drying.

\section{Determination of flavonoid contents}

Concentrations of flavones, flavonols and anthocyanins were analyzed according to Horbowicz et al. (2011, 2015). Briefly, ground samples of buckwheat cotyledons were fivefold extracted by sonication with a mixture of $60 \%$ methanol and $0.4 \%$ trifluoroacetic acid.

HPLC analysis was carried out in a DAD-MS-ESI system (Shimadzu, Japan) equipped with a $250 \times 2.0 \mathrm{~mm}$ i.d. Cadenza CD-C18 $3 \mu \mathrm{m}$ column (Imtakt, Japan). The HPLC system contained two pumps (LC-10 ADVP), DAD detector (SPD-M10 AVP), set to 350 $\mathrm{nm}$ (flavones and flavonols) and $520 \mathrm{~nm}$ (anthocyanins), MS detector (QP8000 $\alpha$ ), autosampler (SIL-10 ADVP), column oven (CTO -10 ASVP) and system controller (SCL-10 AVP). The gradient elution system comprised solvent A (water/acetonitrile/formic acid, 89:6:5) and solvent B (water/acetonitrile/formic acid, 15:80:5). Flavonoid concentrations were calculated with commercial standards supplied by Polyphenols (Norway) and Extrasynthese (France), excluding quercetin-3-O-galactosyl-rhamnoside and cyanidin-3-Ogalactosyl-rhamnoside whose content was calculated based on the standards for rutin and cyanidin-3-O-glucosyl-rhamnoside, respectively. Quercetin-3-O-galactosyl-rhamnoside and cyanidin-3-O-galactosyl-rhamnoside were identified based on previously published data (Wiczkowski et al. 2014). Concentrations of proanthocyanidins were analyzed according to Horbowicz et al. (2011). 


\section{Statistical analysis}

Two-way analysis of variance (ANOVA) with Tukey's post-hoc test were used to assess the significance of differences between the mean flavonoid content in the cotyledons of four buckwheat cultivars exposed to two light intensities. Data were regarded as statistically significant at $P \leq 0.05$. Calculations were performed in Statistica 12 software (StatSoft). The values of the linear Pearson correlation coefficient $(r)$ were calculated to determine the presence of statistically significant relationships between total flavonol, flavone, anthocyanin and procyanidin concentrations.

\section{Results}

In our study, exposure to higher light intensity $\left(360 \mu \mathrm{mol} \cdot \mathrm{m}^{-2} \cdot \mathrm{s}^{-1}\right)$ led to a considerable decrease in the content of all apigenin and luteolin $C$-glycosides relative to low-intensity light conditions $\left(180 \mu \mathrm{mol} \cdot \mathrm{m}^{-2} \cdot \mathrm{s}^{-1}\right)$ (Table 1$)$. The greatest reduction in the levels of these flavonoids was noted in Hruszowska. In contrast, flavonol (glycosides of querce-

Table 1. The effect of light intensity on the content of flavones and flavonols $\left(\mathrm{mg} \cdot \mathrm{g}^{-1}\right.$ dry weight) in the cotyledons of common buckwheat cultivars

\begin{tabular}{|c|c|c|c|c|}
\hline $\begin{array}{l}\text { Light intensity } \\
\left(\mu \mathrm{mol} \cdot \mathrm{m}^{-2} \cdot \mathrm{s}^{-1}\right)\end{array}$ & Hruszowska & Panda & Kora & Red Corolla \\
\hline \multicolumn{5}{|c|}{ Orientin (luteolin-8- $C$-glucoside) } \\
\hline 180 & $1.80 \pm 0.06^{\mathrm{ab}}$ & $1.76 \pm 0.03^{\mathrm{b}}$ & $1.91 \pm 0.05^{\mathrm{a}}$ & $1.10 \pm 0.01^{\mathrm{e}}$ \\
\hline 360 & $1.23 \pm 0.04^{\mathrm{d}}$ & $1.44 \pm 0.05^{\mathrm{c}}$ & $1.50 \pm 0.02^{\mathrm{c}}$ & $0.89 \pm 0.05^{\mathrm{f}}$ \\
\hline \multicolumn{5}{|c|}{ iso-Orientin (luteolin-6-C-glucoside) } \\
\hline 180 & $3.44 \pm 0.04^{\mathrm{a}}$ & $3.22 \pm 0.06^{\mathrm{b}}$ & $3.45 \pm 0.10^{\mathrm{a}}$ & $2.30 \pm 0.02^{\mathrm{e}}$ \\
\hline 360 & $2.54 \pm 0.04^{\mathrm{d}}$ & $2.75 \pm 0.03^{\mathrm{c}}$ & $2.85 \pm 0.02^{\mathrm{c}}$ & $1.94 \pm 0.04^{\mathrm{f}}$ \\
\hline \multicolumn{5}{|c|}{ Vitexin (apigenin-8-C-glucoside) } \\
\hline 180 & $2.26 \pm 0.02^{b}$ & $2.33 \pm 0.08^{\mathrm{ab}}$ & $2.47 \pm 0.08^{\mathrm{a}}$ & $1.17 \pm 0.01^{\mathrm{e}}$ \\
\hline 360 & $1.48 \pm 0.05^{\mathrm{d}}$ & $1.77 \pm 0.06^{\mathrm{c}}$ & $1.88 \pm 0.04^{\mathrm{c}}$ & $0.88 \pm 0.06^{\mathrm{f}}$ \\
\hline \multicolumn{5}{|c|}{ iso-Vitexin (apigenin-6-C-glucoside) } \\
\hline 180 & $5.10 \pm 0.08^{\mathrm{a}}$ & $4.67 \pm 0.08^{b}$ & $5.07 \pm 0.05^{\mathrm{a}}$ & $3.08 \pm 0.07^{\mathrm{e}}$ \\
\hline 360 & $3.93 \pm 0.11^{\mathrm{d}}$ & $3.96 \pm 0.11^{\mathrm{d}}$ & $4.39 \pm 0.01^{\mathrm{c}}$ & $2.78 \pm 0.05^{f}$ \\
\hline \multicolumn{5}{|c|}{ Q-Gal-Rha (quercetin-3-O-galactosyl-rhamnoside) } \\
\hline 180 & $0.29 \pm 0.01^{\mathrm{f}}$ & $1.52 \pm 0.03^{\mathrm{c}}$ & $1.22 \pm 0.06^{\mathrm{e}}$ & $1.38 \pm 0.01^{\mathrm{d}}$ \\
\hline 360 & $1.85 \pm 0.03^{\mathrm{a}}$ & $1.71 \pm 0.05^{\mathrm{b}}$ & $1.51 \pm 0.03^{\mathrm{c}}$ & $1.82 \pm 0.04^{\mathrm{ab}}$ \\
\hline \multicolumn{5}{|c|}{ Rutin (quercetin-3-O-glucosyl-rhamnoside) } \\
\hline 180 & $10.00 \pm 0.28^{\mathrm{e}}$ & $8.01 \pm 0.14^{\mathrm{f}}$ & $7.44 \pm 0.07^{f}$ & $13.15 \pm 0.16^{\mathrm{d}}$ \\
\hline 360 & $12.45 \pm 0.37^{d}$ & $15.16 \pm 0.28^{b}$ & $14.17 \pm 0.07^{c}$ & $23.43 \pm 0.47^{\mathrm{a}}$ \\
\hline
\end{tabular}

The mean values marked with different letters for each flavonoid were statistically significant at $P \leq 0.05$ with Tukey's posthoc test. 
Table 2. The effect of light intensity on the content of anthocyanins and proanthocyanidins ( $\mathrm{mg} \cdot \mathrm{g}^{-1}$ dry weight) in the cotyledons of common buckwheat cultivars

\begin{tabular}{|c|c|c|c|c|}
\hline $\begin{array}{l}\text { Light intensity } \\
\left(\mu \mathrm{mol} \cdot \mathrm{m}^{-2} \cdot \mathrm{s}^{-1}\right)\end{array}$ & Hruszowska & Panda & Kora & Red Corolla \\
\hline \multicolumn{5}{|c|}{ Cyanidin-3-O-galactosyl-rhamnoside } \\
\hline 180 & $0.98 \pm 0.04^{\mathrm{b}}$ & $0.51 \pm 0.01^{\mathrm{g}}$ & $0.57 \pm 0.01^{\mathrm{f}}$ & $0.90 \pm 0.02^{c}$ \\
\hline 360 & $0.67 \pm 0.02^{\mathrm{e}}$ & $0.63 \pm 0.03^{\mathrm{e}}$ & $0.82 \pm 0.03^{\mathrm{d}}$ & $1.29 \pm 0.03^{\mathrm{a}}$ \\
\hline \multicolumn{5}{|c|}{ Cyanidin-3-O-glucosyl-rhamnoside } \\
\hline 180 & $0.33 \pm 0.01^{\mathrm{b}}$ & $0.06 \pm 0.01^{\mathrm{e}}$ & $0.08 \pm 0.01^{\mathrm{e}}$ & $0.31 \pm 0.01^{b}$ \\
\hline 360 & $0.07 \pm 0.01^{\mathrm{e}}$ & $0.11 \pm 0.01^{\mathrm{d}}$ & $0.25 \pm 0.02^{\mathrm{c}}$ & $0.73 \pm 0.02^{\mathrm{a}}$ \\
\hline \multicolumn{5}{|c|}{ Total anthocyanins } \\
\hline 180 & $1.31 \pm 0.03^{b}$ & $0.56 \pm 0.01^{\mathrm{g}}$ & $0.65 \pm 0.01^{\mathrm{f}}$ & $1.21 \pm 0.03^{\mathrm{c}}$ \\
\hline 360 & $0.75 \pm 0.02^{\mathrm{e}}$ & $0.75 \pm 0.03^{\mathrm{e}}$ & $1.07 \pm 0.04^{\mathrm{d}}$ & $2.06 \pm 0.06^{\mathrm{a}}$ \\
\hline \multicolumn{5}{|c|}{ Total proanthocyanidins } \\
\hline 180 & $31.5 \pm 0.2^{\mathrm{cd}}$ & $34.2 \pm 1.0^{\mathrm{ab}}$ & $35.2 \pm 1.1^{\mathrm{a}}$ & $17.4 \pm 0.1^{\mathrm{f}}$ \\
\hline 360 & $24.7 \pm 0.2^{\mathrm{e}}$ & $32.6 \pm 1.0^{\mathrm{bc}}$ & $30.1 \pm 0.7^{\mathrm{d}}$ & $17.2 \pm 0.1^{\mathrm{f}}$ \\
\hline
\end{tabular}

The mean values marked with different letters for each flavonoid were considered statistically significant at $P \leq 0.05$ with Tukey's post-hoc test.

tin) content clearly increased in the cotyledons of seedlings exposed to higher light intensity. A significant, nearly twofold increase in rutin levels was observed in Panda and Kora.

In the cotyledons, higher light intensity increased the accumulation of cyanidin-3-Ogalactosyl-rhamnoside and cyanidin-3-O-glucosyl-rhamnoside except for Hruszowska (Table 2). The cotyledons of Red Corolla were more abundant in rutin, but contained less flavones and proanthocyanidins than other cultivars (Tables 1 and 2). Under exposure to higher light intensities, proanthocyanidin concentrations decreased in Kora and Hruszowska, but not in Red Corolla or Panda. At the same time, exposure to higher light intensity tended to inhibit the growth of aerial parts in Kora and Hruszowska, but in the case of Panda and Red Corolla this phenomenon has not been observed (data not shown).

Table 3. The linear Pearson correlation coefficients $(r)$ and significance of correlations between the content of total flavonols, flavones, anthocyanins and proanthocyanidins in the cotyledons of common buckwheat seedlings exposed to high- and low-intensity light

\begin{tabular}{|l|c|c|c|c|c|c|}
\hline & \multicolumn{2}{|c|}{ Total flavonols } & \multicolumn{2}{c|}{ Total anthocyanins } & \multicolumn{2}{c|}{ Total proanthocyanidins } \\
\cline { 2 - 7 } & $r$ & $\begin{array}{c}\text { level of } \\
\text { significance }\end{array}$ & $r$ & $\begin{array}{c}\text { level of } \\
\text { significance }\end{array}$ & $r$ & $\begin{array}{c}\text { level of } \\
\text { significance }\end{array}$ \\
\hline Total flavones & -0.864 & 0.006 & -0.638 & 0.089 & 0.923 & 0.001 \\
\hline Total flavonols & - & - & 0.754 & 0.031 & -0.705 & 0.051 \\
\hline Total anthocyanins & - & - & - & - & -0.720 & 0.044 \\
\hline
\end{tabular}


A negative correlation was noted between the content of total flavonols and flavones. A similar relationship was observed between the concentrations of proanthocyanidins and flavonols, and between proanthocyanidin and total anthocyanin levels (Table 3; Table S1*).

\section{Discussion}

The presence of light is crucial for the biosynthesis of various types of flavonoids (Jaakola and Hohtola 2010; Zoratti et al. 2014). In apples, the concentrations of phenolic acids, anthocyanins and flavonols increased in response to irradiation, whereas the content of flavanols, procyanidins and dihydrochalcones remained constant (Bakhshi and Arakawa 2006). In our previous study, which was performed on the cotyledons of etiolated buckwheat seedlings the de-etiolation process stimulated the accumulation of all flavonoid types (Horbowicz et al. 2015).

The results of the present study indicate that particular type of flavonoids react differently to the intensity of light (Table 1). Our findings are partially consistent with the results reported by Neugart et al. (2013) in kale (Brassica oleracea var. sabellica), where the concentrations of most quercetin glycosides increased with a rise in PAR levels, and the results reported by Zoratti et al. (2014) in the leaves of Ligustrum vulgare. The concentrations of flavonol aglycones also increased in the leaves of two Brassica species exposed to higher PAR levels (Fallovo et al. 2011). Furthermore, Løvdal et al. (2010) demonstrated that higher light intensity contributed to the accumulation of flavonols in the leaves of tomato plants. In the leaves of Ginkgo biloba, the expression of major genes responsible for flavonoid biosynthesis was highest under $100 \%$ sunlight exposure (Xu et al. 2014). In contrast, Ghasemzadeh et al. (2010) found that the concentrations of most flavonoids in Malaysian ginger (Zingiber officinale) were higher when the plant was grown under light exposure of $310 \mu \mathrm{mol} \cdot \mathrm{m}^{-2} \cdot \mathrm{s}^{-1}$ than $790 \mu \mathrm{mol} \cdot \mathrm{m}^{-2} \cdot \mathrm{s}^{-1}$. Also, Bergquist et al. (2007) reported that the flavonoid content of spinach leaves increased when the plants were grown under shade.

Sunlight exposure of $76 \%$ produced the highest flavonol levels, whereas total flavonoids peaked at 100\% exposure. On the other hand, in the leaves of Anoectochilus formosanus, an increase in light intensity from 10 to $60 \mu \mathrm{mol} \cdot \mathrm{m}^{-2} \cdot \mathrm{s}^{-1}$ provoked a rise in total flavonoid concentrations ( $\mathrm{Ma}$ et al. 2010), but the highest light intensity (90 $\mu \mathrm{mol} \cdot \mathrm{m}^{-2} \cdot \mathrm{s}^{-1}$ ) induced stress, reduced flavonoid accumulation and plant growth. Those differences can probably be attributed to the evolutionary adaptation of various species to growth under different light intensities.

The differences in flavone and flavonol concentrations in plants exposed to various light intensities can probably be attributed to the roles played by those compounds in epidermis and mesophilic cells (Agati and Tattini 2010). There is evidence that the levels of epidermal flavonoids increase under exposure to UV-B irradiation, whereas the con-

*Further details about the Electronic Supplementary Material (ESM) can be found at the end of the article. 
centrations of mesophyll flavonoids and other phenolic compounds remain stable (Burchard et al. 2000). It appears that in common buckwheat cotyledons, quercetin $O$-glycosides are occurred mainly in the epidermal layer, whereas apigenin and luteolin $C$-glucosides are localized in the mesophyll layer. However, this hypothesis requires further investigation and a detailed analysis of flavonoids in epidermal and mesophyll cells. Flavones interact with microbes, insects and other plants, and they belong to the group of phytoalexins (Martens and Mithöfer 2005) which protect plants against pathogenic organisms.

During the present study, higher light intensity increased the accumulation of cyanidin-3-O-galactosyl-rhamnoside and cyanidin-3-O-glucosyl-rhamnoside in the cotyledons of buckwheat cultivars (except Hruszowska), (Table 2). Those results validate the hypothesis stating that anthocyanins play an important role in protecting plants against excessive visible light or UV-B radiation (Burchard et al. 2000; Gould 2004; Agati and Tattini 2010; Fallovo et al. 2011).

Due to its heterozygosity and outbreeding, common buckwheat is characterized by significant genetic variability within a population (Ohnishi 1990). In this study, Red Corolla deserves special attention with respect to its flavonoid content. Red Corolla constitutes a distinct genotype in the group of the evaluated cultivars, while Panda and Kora are genetically closer to Hruszowska. The Red Corolla is a cross between Hruszowska and the Buryatskaya population grown in the steppe region of the former USSR. Red Corolla have reddish cotyledons and leaves, and is more resistant to low temperatures and drought than the remaining cultivars used in this experiment. The differences in the changes of flavonoids content suggest that, presumably, common buckwheat shows intraspecific variation in the response to light intensity. Results of correlation analysis indicate that the increase in flavonol and anthocyanin concentrations in response to higher light intensity is maintained through reduced accumulation of flavones and proanthocyanidins (Table 3; Table S1).

In conclusion, this study demonstrated that the concentrations of quercetin, luteolin and apigenin glycosides in the cotyledons of buckwheat seedlings respond differently to light intensity. Exposure to higher light intensity decreased the content of all flavone glycosides, but induced a considerable increase in flavonol levels, in particular rutin. To the best of our knowledge, this is the first evidence to demonstrate the contrary responses of plant flavonols and flavones to light intensity. Exposure to higher light intensity also increased the anthocyanin content in the cotyledons of buckwheat seedlings, which is consistent with the findings of other authors. Our findings indicate that quercetin $O$-glycosides can play a similar role in the cotyledons of common buckwheat seedlings. Significant correlations were found between the content of flavones, flavonols, anthocyanins and proanthocyanidins, which suggests that the increase in flavonol and anthocyanin concentrations in response to higher light intensity is maintained through reduced accumulation of flavones and proanthocyanidins. 


\section{Acknowledgements}

The research was supported by the Ministry of Science and Higher Education (Poland) as a part of the statutory activities of the Faculty of Natural Sciences at the Siedlce University of Natural Sciences and Humanities (no 13/91/S).

\section{References}

Agati, G., Tattini, M. 2010. Multiple functional roles of flavonoids in photoprotection. New Phytol. 186:786793.

Bakhshi, D., Arakawa, O. 2006. Induction of phenolic compounds biosynthesis with light irradiation in the flesh of red and yellow apples. J. Appl. Hort. 8:101-104.

Bergquist, S., Gertsson, U., Nordmark, L.Y., Olsson, M.E. 2007. Effects of shade nettings, sowing time and storage on baby spinach flavonoids. J. Sci. Food Agric. 87:2464-2471.

Burchard, P., Bilger, W., Weissenböck, G. 2000. Contribution of hydroxycinnamates and flavonoids to epidermal shielding of UV-A and UV-B radiation in developing rye primary leaves as measured by ultravioletinduced chlorophyll fluorescence measurements. Plant Cell Env. 23:1373-1380.

Del Rio, D., Rodriguez-Mateos, A., Spencer, J.P.E., Tognolini, M., Borges, G., Crozier, A. 2013. Dietary (poly) phenolics in human health: Structures, bioavailability, and evidence of protective effects against chronic diseases. Antioxid. Redox Sign. 18:1818-1892.

Fallovo, C., Schreiner, M., Schwarz, D., Colla, G., Krumbein, A. 2011. Phytochemical changes induced by different nitrogen supply forms and radiation levels in two leafy Brassica species. J. Agric. Food Chem. 59:4198-4207.

Ghasemzadeh, A., Jaafar, H.Z.E., Rahmat, A. 2010. Synthesis of phenolics and flavonoids in ginger (Zingiber officinale Roscoe) and their effects on photosynthesis rate. Int. J. Mol. Sci. 11:4539-4555.

Gould, K.S. 2004. Nature's Swiss army knife: The diverse protective roles of anthocyanins in leaves. J. Biomed. Biotechnol. 5:314-320.

Gupta, N., Sharma, S.K., Rana, J.C., Chauhan, R.S. 2011. Expression of flavonoid biosynthesis genes vis-à-vis rutin content variation in different growth stages of Fagopyrum species. J. Plant Physiol. 168:2117-2123.

Hemm, M.R., Rider, S.D., Ogas, J., Murry, D.J., Chapple, C. 2004. Light induces phenylpropanoid metabolism in Arabidopsis roots. Plant J. 38:765-778.

Horbowicz, M., Wiczkowski, W., Koczkodaj, D., Saniewski, M. 2011. Effects of methyl jasmonate on accumulation of flavonoids in seedlings of common buckwheat (Fagopyrum esculentum Moench). Acta Biol. Hung. 62:265-278.

Horbowicz, M., Wiczkowski, W., Szawara-Nowak, D., Sawicki, T., Kosson, R., Sytykiewicz, H. 2015. The level of flavonoids and amines in de-etiolated and methyl jasmonate treated seedlings of common buckwheat. Phytochem. Lett. 13:15-19.

Jaakola, L., Hohtola, A. 2010. Effect of latitude on flavonoid biosynthesis in plants. Plant Cell Env. 33:12391247.

Kalinová, J., Dadáková, E. 2006. Varietal and year variation of rutin content in common buckwheat (Fagopyrum esculentum Moench). Cereal Res. Commun. 34:1315-1321.

Kalinová, J., Dadáková, E. 2012. Influence of sowing date and stand density on rutin level in buckwheat. Cereal Res. Commun. 41:348-358.

Kim, S.J., Kawaharada, C., Suzuki, T., Saito, K., Hashimoto, N., Takigawa, S., Yamauchi, H. 2006. Effect of natural light periods on rutin, free amino acid and vitamin $\mathrm{C}$ contents in the sprouts of common (Fagopyrum esculentum Moench) and tartary (F. tataricum Gaertn.) buckwheats. Food Sci. Technol. Res. 12:199-205.

Liu, C.Z., Guo, C., Wang, Y.C., Ouyang, F. 2002. Effect of light irradiation on hairy root growth and artemisinin biosynthesis of Artemisia annua. Process. Biochem. 38:581-585.

Løvdal, T., Olsen, K.M., Slimestad, R., Verheul, M., Lillo, C. 2010. Synergetic effects of nitrogen depletion, temperature, and light on the content of phenolic compounds and gene expression in leaves of tomato. Phytochem. 71:605-613. 
Ma, Z., Li, S., Zhang, M., Jiang, S., Xiao, Y. 2010. Light intensity affects growth, photosynthetic capability, and total flavonoid accumulation of Anoectochilus plants. Hort. Sci. 45:863-867.

Martens, S., Mithöfer, A. 2005. Flavones and flavone synthases. Phytochem. 66:2399-2407.

Neugart, S., Fiol, M., Schreiner, M., Rohn, S., Zrenner, R., Kroh, L.W., Krumbein, A. 2013. Low and moderate photosynthetically active radiation affects the flavonol glycosides and hydroxycinnamic acid derivatives in kale (Brassica oleracea var. sabellica) dependent on two low temperatures. Plant Physiol. Biochem. 72:161-168.

Ohnishi, O. 1990. Analyses of genetic variants in common buckwheat, Fagopyrum esculentum Moench: a review. Fagopyrum 10:12-22.

Suzuki, T., Morishita, T., Kim, S.J., Park, S.U., Woo, S.H., Noa, T., Takigawa, S. 2015. Physiological roles of rutin in the buckwheat plant. Jpn. Agr. Res. Quart. 49:37-43.

Wiczkowski, W., Szawara-Nowak, D., Dębski, H., Mitrus, J., Horbowicz, M. 2014. Comparison of flavonoids profile in sprouts of common buckwheat cultivars and wild tartary buckwheat. Int. J. Food. Sci. Tech. 49:1977-1984.

Winkel-Shirley, B. 2001. Flavonoid biosynthesis. A colorful model for genetics, biochemistry, cell biology, and biotechnology. Plant Physiol. 126:485-493.

Xu, Y., Wang, G., Cao, F., Zhu, C., Wang, G., El-Kassaby, Y.A. 2014. Light intensity affects the growth and flavonol biosynthesis of ginkgo (Ginkgo biloba L.). New Forest 45:765-776.

Zoratti, L., Karppinen, K., Luengo Escobar, A., Häggman, H., Jaakola, L. 2014. Light-controlled flavonoid biosynthesis in fruits. Front. Plant Sci. 5:534.

\section{Electronic Supplementary Material (ESM)}

Electronic Supplementary Material (ESM) associated with this article can be found at the website of CRC at http://www.akademiai.com/content/120427/

Electronic Supplementary Table S1. Results of the two-way analysis of variance between the mean flavonoid contents in the cotyledons of four buckwheat cultivars exposed to two light intensities 